\title{
Functional Fibrinogen Measurement
}

National Cancer Institute

\section{Source}

National Cancer Institute. Functional Fibrinogen Measurement. NCI Thesaurus. Code C139075.

The determination of the amount of functional fibrinogen present in a sample. 